\title{
Impact of neighbourhood food environment on food consumption in children aged 9-10 years in the UK SPEEDY (Sport, Physical Activity and Eating behaviour: Environmental Determinants in Young people) study
}

\author{
Paula Skidmore ${ }^{1}$, Ailsa Welch ${ }^{1}$, Esther van Sluijs ${ }^{2}$, Andrew Jones ${ }^{3}$, lan Harvey ${ }^{1}$, \\ Flo Harrison ${ }^{3}$, Simon Griffin ${ }^{2}$ and Aedín Cassidy ${ }^{1, *}$ \\ ${ }^{1}$ School of Medicine, University of East Anglia, Norwich NR4 7JT, UK: ${ }^{2}$ Medical Research Council Epidemiology \\ Unit, Institute of Metabolic Science, Addenbrookes Hospital, Cambridge, UK: ${ }^{3}$ School of Environmental \\ Sciences, University of East Anglia, Norwich, UK
}

Submitted 22 May 2009: Accepted 6 October 2009: First published online 16 November 2009

\begin{abstract}
Objective: Poor diet in childhood increases risk of obesity but the relationship between access to food and children's food choice is underexplored. We determined relationships between distance to and density of food outlets on children's food choice.

Design: Children ( $n$ 1721) aged 9-10 years who participated in a cross-sectional study from a sample of state and private schools across urban and rural areas. Food consumption was reported using a short validated FFQ. A Geographic Information System was used to determine proximity to local food outlets. Multivariable regression analyses were performed to determine associations between food consumption and distance to and density of local food outlets. Setting: Norfolk, England.

Subjects: Boys ( $n$ 754) and girls ( $n$ 967) aged 9-10 years.

Results: The impact of distance to or density of food outlets on food choice was small after adjustment. Living further away from a supermarket increased portions of fruit $(0 \cdot 11$ portions/week per $1 \mathrm{~km}$ increase in distance to nearest supermarket, $P<0 \cdot 05)$ and vegetables $(0 \cdot 11$ portions/week, $P<0 \cdot 05)$ consumed. Living closer to convenience stores was also associated with an increased consumption of crisps, chocolate and white bread. Density of supermarkets was associated with both an increase in vegetable intake $(0.31$ portions/week, $P<0.05)$ and unhealthy foods.

Conclusions: Distance to and density of food outlets are both associated with children's food choice, although the impact appears to be small and the relationship is complex. However, the effects of individual foods combined could be important, particularly as even small differences in intake can impact on body weight over time.
\end{abstract}

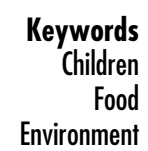

The impact of poor childhood nutrition has consequences for both short-term and long-term health ${ }^{(1,2)}$ and the escalating rates of obesity in childhood are becoming a significant public health issue ${ }^{(3)}$. A number of factors contribute to poor food intake, including socio-economic status, parental and child food choice and preferences, and the accessibility of foods. There is growing evidence to show that those of lower socio-economic status have to spend a higher proportion of their income on food ${ }^{(4)}$ and tend to consume less healthy diets ${ }^{(5,6)}$.

Research in the USA has shown that people living in areas of low socio-economic status have poorer access to supermarkets, resulting in less access to healthier foods, and the foods that could be purchased were more expensive $^{(7)}$. Other research shows that those living in deprived areas had much greater access to fast-food retailers and other retailers selling less healthy products $^{(8-11)}$. To date there has been limited and inconsistent evidence that these 'food deserts', where residents have limited access to healthy food, exist in the $\mathrm{UK}^{(12)}$. However, the available previous research has focused on more densely populated urban areas ${ }^{(13)}$ and there may be particular problems with access to or availability of healthier foods for those living in smaller towns and villages. Furthermore, there have been few studies on the relationship between neighbourhood food outlets and 
food intake in children, although the findings from the limited available evidence suggest that children living in areas with higher densities of fast-food retailers tend to make poorer dietary choices ${ }^{(14-16)}$.

While there has been some previous research on the role of the neighbourhood environment in determining food choice, there have been limited studies employing Geographic Information Systems (GIS) ${ }^{(14,16-19)}$ in order to produce objective indicators of different domains of the local food environment, such as distance to and density of food outlets. Furthermore, all previous studies of children that have used GIS data have focused only on fruit and vegetable consumption ${ }^{(14,16,18)}$, whereas the food environment is likely to influence other food choices as well.

Since childhood nutrition is important for future health, and rates of childhood obesity are rising, it is important to understand the relationship between food intake and food access among this group. Therefore the present study was undertaken to investigate the relationship between distance to and density of foods in the local neighbourhood and both healthy and less healthy food choices in a population of 9- to 10-year-old children in the UK.

\section{Methods}

\section{SPEEDY}

The SPEEDY (Sport, Physical Activity and Eating behaviour: Environmental Determinants in Young people) study was set up to quantify the potential correlates of levels of physical activity and dietary habits in 9- to 10-year-old schoolchildren (Year 5) in the county of Norfolk, England. A detailed description of the methods adopted has been published previously ${ }^{(20)}$. Ethical approval for the SPEEDY study was obtained from the University of East Anglia local research ethics committee.

\section{Sampling}

A cluster sampling strategy based on schools was adopted. Schools in Norfolk with eligible children attending were sampled to attain heterogeneity in location. The urban/rural status of all potentially eligible schools was determined using Bibby and Shepherd's classification of rurality $^{(21)}$, and one of four area profiles, 'Urban' $(>10000$ residents), 'Town and fringe', 'Village' and 'Hamlet and isolated dwelling', was assigned to each. In total, 157 schools were approached and measurements were conducted at ninety-two schools. All Year 5 children within participating schools ( $n$ 3619) were invited to participate and parental informed consent was obtained from 2064 children $(57 \cdot 0 \%$ response rate).

\section{Examination of children at school}

Data collection was performed during the summer term of 2007 (April to July), and participating children were visited at school by teams of two or more trained research assistants. They collected a range of data according to standard operating procedures including anthropometry, demographic information, school-level information, and details of children's home and neighbourhood environment. A questionnaire was also completed by a parent or main carer of each child.

Children self-reported their date of birth, and age was calculated at time of examination. The parent or main carer self-reported their age at leaving full-time education (in categories). Simple non-invasive anthropometry measures were conducted using standardised procedures, with children dressed in light clothing. Portable Leicester height measures (Seca, Birmingham, UK) were used to measure height to the nearest millimetre. A non-segmental bioimpedance scale (type TBF-300A; Tanita, Tokyo, Japan) was used to measure weight (to the nearest $0 \cdot 1 \mathrm{~kg}$ ) and impedance. BMI was calculated as weight (in kilograms) divided by the square of height (in metres). Obesity status was determined using gender- and age-dependent cut-off points ${ }^{(22)}$. Index of Multiple Deprivation (IMD) scores ${ }^{(23)}$, a measure of area material deprivation, were assigned to each child based on the location of their residential postcode and results were allocated into quintiles of deprivation (NQD), using the national categories ${ }^{(23)}$. A higher IMD score reflects a higher level of deprivation.

\section{Dietary assessment}

Food choice was assessed using an adapted version of the Health Behaviour in School Children (HBSC) questionnaire, which was designed to collect self-reported information on food choices in children in Europe and North America ${ }^{(24)}$. It consists of a fifteen-item questionnaire of the most commonly consumed foods in participating countries that has been previously validated and can be used for ranking participants for most food items ${ }^{(24)}$. Adaptations to the items to increase applicability to our age group included removing alcohol consumption, adding fruit juice consumption, and separating sweets and chocolate into two separate items. The children reported the frequency of consumption on a 7-point scale ('never', '<1/week', '1/week', '2-4d/week', '5-6d/week', 'once a day, every day', 'every day, more than once') ${ }^{(24)}$.

\section{Food accessibility}

The computation of the accessibility measures was undertaken in the ArcGIS package (ESRI Inc., Redlands, CA, USA). All facilities in the study area serving food for consumption off the premises were mapped based on their location identified in the UK Ordnance Survey 'Points of Interest' database. 'Points of Interest' provides data on the location of commercial facilities, which are coded according to type. For this work we classified each food retailer according to whether it was a supermarket (a large food store selling a wide variety of foods), a convenience store (a small neighbourhood retailer with more restricted choice), a takeaway (a retailer selling hot food for 
consumption off the premises) or another type of food shop. Other food retailers included greengrocers, bakers, butchers, delicatessens and other independent food retailers.

Two measures of accessibility were computed for each outlet, both based on a pedestrian network created in the GIS using the location of roads and public footpaths. The first measure was the network walking distance from the child's home to the nearest food retailer of each type, which was calculated in kilometres. The second measure was of the density (per square kilometre) of each type of facility within the neighbourhood of each child. The neighbourhood was delineated as the area within $800 \mathrm{~m}$ (roughly equating to a $10 \mathrm{~min}$ walk) along the network from a child's home.

\section{Statistical analyses}

Descriptive data were summarised as means with standard deviations or percentages. Differences in overweight and obesity between boys and girls were investigated using the $\chi^{2}$ test, while all other gender differences were determined using Student's $t$ test.

Regression analyses were performed using generalized estimating equations and included a food environment variable (either distance to or density or food outlet) and a single food variable. A two-level hierarchical structure was used to allow for the clustering in food consumption behaviours among children attending the same schools ${ }^{(25)}$. The influence of confounding variables was assessed by fitting two models, with Model 1 including gender and clustered by school. As both individual- and neighbourhood-level deprivation are associated with food choice, Model 2 was adjusted for gender, BMI, parental education, IMD and urban/rural location and also clustered by school. All regression coefficients are presented as portions per week. The $\beta$ coefficients are presented per kilometre increase for distance variables, and per outlet per square kilometre increase for density variables. All analyses were performed using the STATA statistical software package version 10 (StataCorp LP, College Station, TX, USA).

\section{Results}

Of the 2064 children recruited to the study, GIS and IMD data were available for 2023 (98\%) children and 2056 (99.6\%) completed the FFQ. BMI Z-scores were calculated for $93 \%$ of children ( $n$ 1923) and data on parental education was available for $91.4 \%$ of participants ( $n$ 1887). The number of participants with data for all variables was 1721 ( $83 \%$ of the original sample).

In our study population, $77 \%$ of children were of normal weight, with $23 \%$ defined as overweight or obese (Table 1 ). There were gender differences, with a lower percentage of girls being of normal weight compared with boys $(P=0 \cdot 005)$ and significant differences in intakes of all foods apart from fruit juices, crisps and white bread (Table 1). The distribution of IMD scores (Table 2) shows that $21 \%$ of the children lived in households that were located in areas falling in NQD categories 1 and 2 (most deprived), while $47 \%$ were in categories 4 and 5 (least deprived). Only 20\% of the children lived in households where parental education continued after the age of 18 years. About 39\% of participants lived in an urban area and the majority of subjects lived over a kilometre from their nearest food retailer or takeaway. Mean density of food outlets ranged from $0 \cdot 3$ to $1 \cdot 9 / \mathrm{km}^{2}$, with the accessibility and provision of supermarkets being the poorest (Table 2).

Tables 3 and 4 show the relationship between weekly food intake frequency and distance to and density of food

Table 1 Rates of overweight and obesity and frequency of food consumption in the study population: boys and girls aged 9-10 years, Norfolk, England, April-July 2007

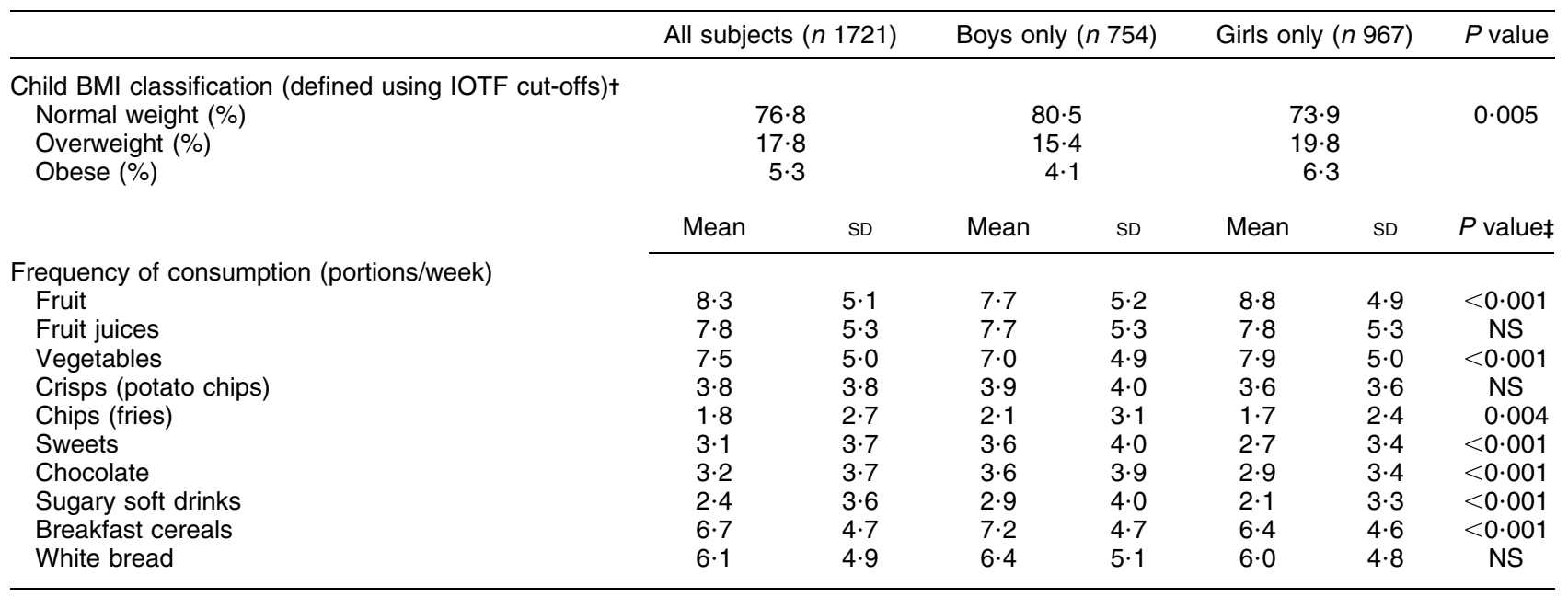

IOTF, International Obesity Taskforce.

tObesity status was determined using gender- and age-dependent cut points according to the method of Cole et al. ${ }^{(22)}$. $\ddagger P$ for the difference between boys and girls. 
Table 2 Characteristics of the study population and access to food outlets: boys and girls aged 9-10 years, Norfolk, England, April-July 2007

\begin{tabular}{|c|c|c|}
\hline Characteristic & & Prevalence $(\%)$ \\
\hline \multirow[t]{5}{*}{ National deprivation index category (NQD; $1=$ most deprived) } & NQD 1 & $8 \cdot 0$ \\
\hline & NQD 2 & $13 \cdot 1$ \\
\hline & NQD 3 & $32 \cdot 1$ \\
\hline & NQD 4 & $25 \cdot 9$ \\
\hline & NQD 5 & $20 \cdot 9$ \\
\hline \multirow[t]{3}{*}{ Parental age (years) at end of education } & $\leq 16$ & $47 \cdot 5$ \\
\hline & 16 to 18 & $32 \cdot 3$ \\
\hline & $>18$ & $20 \cdot 2$ \\
\hline \multirow[t]{4}{*}{ Home location } & Urban & $38 \cdot 5$ \\
\hline & Town and fringe & $28 \cdot 4$ \\
\hline & Village & $26 \cdot 2$ \\
\hline & Hamlet and isolated dwelling & $6 \cdot 9$ \\
\hline \multirow{4}{*}{ Distance to nearest supermarket $(\mathrm{km})$} & $<0.5$ & $8 \cdot 0$ \\
\hline & 0.5 to $<1.0$ & $20 \cdot 0$ \\
\hline & $1 \cdot 0$ to $<2 \cdot 0$ & $22 \cdot 4$ \\
\hline & $\geq 2 \cdot 0$ & $49 \cdot 6$ \\
\hline \multirow[t]{4}{*}{ Distance to nearest convenience store $(\mathrm{km})$} & $<0.5$ & $18 \cdot 8$ \\
\hline & 0.5 to $<1.0$ & $25 \cdot 3$ \\
\hline & $1 \cdot 0$ to $<2 \cdot 0$ & $20 \cdot 6$ \\
\hline & $\geq 2 \cdot 0$ & $35 \cdot 3$ \\
\hline \multirow[t]{4}{*}{ Distance to nearest other food shop $(\mathrm{km})$} & $<0.5$ & $17 \cdot 4$ \\
\hline & 0.5 to $<1.0$ & $23 \cdot 6$ \\
\hline & $1 \cdot 0$ to $<2 \cdot 0$ & $26 \cdot 4$ \\
\hline & $\geq 2 \cdot 0$ & $32 \cdot 6$ \\
\hline \multirow{4}{*}{ Distance to nearest takeaway $(\mathrm{km})$} & $<0.5$ & $19 \cdot 7$ \\
\hline & 0.5 to $<1.0$ & $24 \cdot 7$ \\
\hline & $1 \cdot 0$ to $<2 \cdot 0$ & $22 \cdot 0$ \\
\hline & $\geq 2 \cdot 0$ & $33 \cdot 6$ \\
\hline \multirow[t]{4}{*}{ Number of neighbourhood supermarkets per $\mathrm{km}^{2}$} & None & $77 \cdot 7$ \\
\hline & Up to 1 & $7 \cdot 4$ \\
\hline & Between 1 and 2 & $10 \cdot 6$ \\
\hline & More than 2 & $4 \cdot 2$ \\
\hline \multirow{4}{*}{ Number of neighbourhood convenience stores per $\mathrm{km}^{2}$} & None & $62 \cdot 6$ \\
\hline & Up to 1 & $7 \cdot 2$ \\
\hline & Between 1 and 2 & $17 \cdot 0$ \\
\hline & More than 2 & $13 \cdot 2$ \\
\hline \multirow[t]{4}{*}{ Number of other neighbourhood food stores per $\mathrm{km}^{2}$} & None & $67 \cdot 5$ \\
\hline & Up to 1 & $6 \cdot 0$ \\
\hline & Between 1 and 2 & $9 \cdot 4$ \\
\hline & More than 2 & $17 \cdot 1$ \\
\hline \multirow[t]{4}{*}{ Number of neighbourhood takeaways per $\mathrm{km}^{2}$} & None & $62 \cdot 2$ \\
\hline & Up to 1 & $4 \cdot 7$ \\
\hline & Between 1 and 2 & $9 \cdot 9$ \\
\hline & More than 2 & $23 \cdot 2$ \\
\hline
\end{tabular}

outlets, respectively. Distance to and density of food outlets did not appear to impact on the consumption of the following foods included in the HBSC questionnaire: whole milk, semi-skimmed or skimmed milk, brown or wholemeal bread, cheese or sugar-free soft drinks (data not shown).

\section{Supermarkets}

Living further away from a supermarket was associated with a generally more favourable food intake; fruit intake was significantly higher $(0 \cdot 11$ portions/week increase per $1 \mathrm{~km}$ increase in distance from a supermarket after multivariate adjustment, $P<0.05)$ as was vegetable intake $(0.11$ portions/week, $P<0 \cdot 05)$, while white bread intake was significantly lower $(-0 \cdot 11$ portions/week, $P<0 \cdot 05$; Table 3$)$. Higher density of supermarkets in a neighbourhood was related to an increase in vegetable consumption
$(0 \cdot 31$ portions/week per unit increase in food outlets in the surrounding $1 \mathrm{~km}^{2}$ after multivariable adjustment, $P<0 \cdot 05)$. A similar increase in fruit intake was observed although this did not reach statistical significance. There were also significant increases in intake of sweets, sugary soft drinks, breakfast cereals and white bread for each additional supermarket per square kilometre in Model 1, but these became non-significant in Model 2 .

\section{Convenience stores}

Living further away from a convenience store was associated with a more favourable food intake (Table 3), although the finding of increased vegetable intake with increasing distance became non-significant after full adjustment. Nevertheless, reported consumption of crisps, chips, sweets, chocolate and white bread all declined with increasing distance from convenience stores in both models. 
Table 3 The relationship between distance to food outlets and food intake frequency per week: boys and girls aged 9-10 years, Norfolk, England, April-July 2007

\begin{tabular}{|c|c|c|c|c|c|c|c|c|c|}
\hline & \multirow[b]{2}{*}{ Model } & \multicolumn{2}{|c|}{ Distance to nearest supermarket } & \multicolumn{2}{|c|}{ Distance to nearest convenience store } & \multicolumn{2}{|c|}{ Distance to nearest other food shop } & \multicolumn{2}{|c|}{ Distance to nearest takeaway } \\
\hline & & $\beta$ (per km increase) & $95 \% \mathrm{Cl}$ & $\beta$ (per km increase) & $95 \% \mathrm{Cl}$ & $\beta$ (per km increase) & $95 \% \mathrm{Cl}$ & $\beta$ (per km increase) & $95 \% \mathrm{Cl}$ \\
\hline \multirow[t]{2}{*}{ Fruit } & 1 & 0.06 & $-0.02,0.15$ & 0.03 & $-0.07,0.14$ & 0.04 & $-0 \cdot 08,0 \cdot 17$ & 0.05 & $-0.07,0.17$ \\
\hline & 2 & $0 \cdot 11^{*}$ & $0.01,0.21$ & 0.05 & $-0.08,0.19$ & 0.07 & $-0.07,0.22$ & 0.07 & $-0.08,0.22$ \\
\hline \multirow[t]{2}{*}{ Fruit juices } & 1 & -0.08 & $-0.17,0.01$ & $-0 \cdot 10^{*}$ & $-0.20,0.00$ & -0.09 & $-0.22,0.05$ & -0.05 & $-0.18,0.08$ \\
\hline & 2 & -0.03 & $-0.14,0.08$ & -0.05 & $-0.17,0.08$ & -0.02 & $-0 \cdot 17,0 \cdot 12$ & 0.04 & $-0 \cdot 13,0.20$ \\
\hline \multirow{2}{*}{ Vegetables } & 1 & $0 \cdot 10^{*}$ & $0.01,0.19$ & $0 \cdot 12^{\star \star}$ & $0.03,0.21$ & $0 \cdot 11$ & $-0.01,0.24$ & $0 \cdot 12^{*}$ & $0.02,0.22$ \\
\hline & 2 & $0 \cdot 11^{*}$ & $0.00,0.22$ & 0.11 & $-0.01,0.23$ & 0.08 & $-0.07,0.22$ & 0.10 & $-0.03,0.23$ \\
\hline \multirow{2}{*}{ Crisps } & 1 & -0.03 & $-0.10,0.04$ & $-0 \cdot 13^{\star \star}$ & $-0.20,-0.06$ & $-0 \cdot 11^{*}$ & $-0.21,-0.01$ & $-0.11^{*}$ & $-0.20,-0.02$ \\
\hline & 2 & -0.01 & $-0.10,-0.08$ & $-0 \cdot 16^{\star \star}$ & $-0.25,-0.06$ & -0.09 & $-0.21,0.02$ & $-0 \cdot 12^{*}$ & $-0.24,-0.01$ \\
\hline \multirow[t]{2}{*}{ Chips } & 1 & $-0.04^{*}$ & $-0.08,0.00$ & $-0 \cdot 10^{\star \star}$ & $-0.15,-0.06$ & $-0 \cdot 10^{\star \star}$ & $-0 \cdot 16,-0.04$ & $-0.09^{\star \star}$ & $-0.16,-0.02$ \\
\hline & 2 & -0.02 & $-0.08,0.04$ & $-0.09^{\star \star}$ & $-0.16,-0.03$ & -0.07 & $-0.14,0.01$ & -0.08 & $-0.17,0.01$ \\
\hline \multirow{2}{*}{ Sweets } & 1 & $-0.07^{\star}$ & $-0.12,-0.01$ & $-0 \cdot 13^{\star *}$ & $-0.21,-0.05$ & $-0 \cdot 12^{\star \star}$ & $-0 \cdot 19,-0.04$ & $-0 \cdot 12^{\star *}$ & $-0.20,-0.05$ \\
\hline & 2 & -0.02 & $-0.10,0.06$ & $-0 \cdot 10^{\star}$ & $-0.20,0.00$ & -0.06 & $-0 \cdot 16,0.05$ & -0.09 & $-0.20,0.01$ \\
\hline \multirow[t]{2}{*}{ Chocolate } & 1 & -0.03 & $-0.09,0.03$ & $-0.09^{*}$ & $-0.17,-0.01$ & -0.06 & $-0.16,0.04$ & $-0 \cdot 10^{*}$ & $-0.19,-0.02$ \\
\hline & 2 & -0.02 & $-0.11,0.06$ & $-0.09^{*}$ & $-0.20,-0.01$ & -0.04 & $-0.17,0.09$ & $-0 \cdot 12^{*}$ & $-0.22,-0.02$ \\
\hline \multirow[t]{2}{*}{ Sugary soft drinks } & 1 & -0.04 & $-0 \cdot 10,0.02$ & $-0 \cdot 10^{* *}$ & $-0.18,-0.03$ & -0.08 & $-0.17,0.02$ & $-0 \cdot 13^{\star \star}$ & $-0.21,-0.05$ \\
\hline & 2 & 0.01 & $-0.07,0.09$ & -0.07 & $-0.17,0.02$ & -0.01 & $-0 \cdot 12,0 \cdot 10$ & $-0 \cdot 10^{*}$ & $-0.20,-0.01$ \\
\hline \multirow{2}{*}{ Breakfast cereals } & 1 & -0.04 & $-0.10,0.02$ & -0.09 & $-0.19,0.01$ & -0.06 & $-0.20,0.09$ & -0.09 & $-0.21,0.03$ \\
\hline & 2 & 0.04 & $-0.05,0.12$ & -0.02 & $-0.15,0 \cdot 11$ & 0.04 & $-0.12,0.21$ & 0.01 & $-0.16,0.14$ \\
\hline \multirow[t]{2}{*}{ White bread } & 1 & $-0 \cdot 15^{\star \star}$ & $-0.23,-0.08$ & $-0 \cdot 22^{\star \star}$ & $-0.31,-0.12$ & $-0 \cdot 16^{\star}$ & $-0.29,-0.04$ & $-0 \cdot 21^{\star *}$ & $-0.31,-0.11$ \\
\hline & 2 & $-0 \cdot 11^{*}$ & $-0.21,-0.01$ & $-0 \cdot 19^{\star \star}$ & $-0.30,-0.07$ & -0.07 & $-0.20,0.07$ & $-0 \cdot 17^{\star}$ & $-0.29,-0.05$ \\
\hline
\end{tabular}

Model 1: adjusted for gender, clustered by school.

Model 2: adjusted for BMI, parental education, Index of Multiple Deprivation score, location and gender, clustered by school.

Coefficient was significant: ${ }^{\star} P<0.05,{ }^{\star \star} P<0 \cdot 01$. 
Table 4 The relationship between neighbourhood density of food outlets and food intake frequency per week: boys and girls aged 9-10 years, Norfolk, England, April-July 2007

\begin{tabular}{|c|c|c|c|c|c|c|c|c|c|}
\hline & \multirow[b]{2}{*}{ Model } & \multicolumn{2}{|c|}{ Number of supermarkets per $\mathrm{km}^{2}$} & \multicolumn{2}{|c|}{ Number of convenience stores per $\mathrm{km}^{2}$} & \multicolumn{2}{|c|}{ Number of other food shops per $\mathrm{km}^{2}$} & \multicolumn{2}{|c|}{ Number of other takeaways per $\mathrm{km}^{2}$} \\
\hline & & $\beta$ (per unit increase) & $95 \% \mathrm{Cl}$ & $\beta$ (per unit increase) & $95 \% \mathrm{Cl}$ & $\beta$ (per unit increase) & $95 \% \mathrm{Cl}$ & $\beta$ (per unit increase) & $95 \% \mathrm{Cl}$ \\
\hline \multirow[t]{2}{*}{ Fruit } & 1 & $0 \cdot 18$ & $-0.11,0.48$ & $0 \cdot 15^{\star}$ & $-0.01,0.30$ & 0.06 & $-0.04,0.16$ & 0.09 & $-0 \cdot 03,0 \cdot 18$ \\
\hline & 2 & 0.26 & $-0.05,0.57$ & $0 \cdot 13$ & $-0.06,0.32$ & 0.07 & $-0.03,0.18$ & 0.09 & $-0.01,0.19$ \\
\hline \multirow[t]{2}{*}{ Fruit juices } & 1 & $0 \cdot 17$ & $-0.22,0.44$ & $0 \cdot 33^{\star *}$ & $0 \cdot 18,0 \cdot 48$ & 0.06 & $-0.08,0.20$ & $0 \cdot 12^{*}$ & $0.00,0.24$ \\
\hline & 2 & -0.08 & $-0.42,0.25$ & $0 \cdot 25^{\star \star}$ & $0.05,0.45$ & 0.01 & $-0 \cdot 12,0 \cdot 13$ & 0.06 & $-0.07,0.20$ \\
\hline \multirow[t]{2}{*}{ Vegetables } & 1 & $0 \cdot 15$ & $-0.19,0.49$ & 0.04 & $-0.15,0.23$ & 0.02 & $-0.07,0.11$ & 0.08 & $-0.03,0.18$ \\
\hline & 2 & $0.31^{*}$ & $0.00,0.63$ & 0.09 & $-0 \cdot 10,0 \cdot 27$ & 0.05 & $-0.03,0.14$ & $0 \cdot 12^{*}$ & $0.01,0.23$ \\
\hline \multirow[t]{2}{*}{ Crisps } & 1 & -0.03 & $-0.29,0.22$ & 0.04 & $-0 \cdot 10,0 \cdot 17$ & 0.01 & $-0.07,0.10$ & 0.02 & $-0.05,0.09$ \\
\hline & 2 & $-0 \cdot 14$ & $-0 \cdot 48,0 \cdot 14$ & 0.03 & $-0 \cdot 13,0 \cdot 18$ & -0.01 & $-0.09,0.07$ & 0.01 & $-0.07,0.09$ \\
\hline \multirow[t]{2}{*}{ Chips } & 1 & $0 \cdot 19$ & $-0.02,0.41$ & $0 \cdot 10$ & $-0.01,0.19$ & 0.04 & $-0 \cdot 01,0 \cdot 10$ & $0 \cdot 05^{\star}$ & $0.00,0.08$ \\
\hline & 2 & $0 \cdot 12$ & $-0.14,0.37$ & 0.06 & $-0.06,0.19$ & 0.02 & $-0.03,0.07$ & 0.03 & $-0.02,0.08$ \\
\hline \multirow[t]{2}{*}{ Sweets } & 1 & $0 \cdot 36^{*}$ & $0.09,0.64$ & 0.08 & $-0.05,0.21$ & 0.05 & $-0.04,0.14$ & 0.05 & $-0.03,0.12$ \\
\hline & 2 & $0 \cdot 26$ & $-0.04,0.56$ & 0.00 & $-0 \cdot 15,0.14$ & 0.02 & $-0.07,0.11$ & 0.00 & $-0.08,0.09$ \\
\hline \multirow[t]{2}{*}{ Chocolate } & 1 & $0 \cdot 15$ & $-0.15,0.45$ & 0.03 & $-0.11,0.17$ & 0.00 & $-0.08,0.08$ & -0.01 & $-0.09,0.07$ \\
\hline & 2 & $0 \cdot 12$ & $-0.19,0.43$ & 0.02 & $-0 \cdot 14,0 \cdot 17$ & 0.00 & $-0.08,0.08$ & -0.03 & $-0.12,0.06$ \\
\hline \multirow[t]{2}{*}{ Sugary soft drinks } & 1 & $0 \cdot 26^{*}$ & $0.00,0.52$ & $0 \cdot 11$ & $-0.06,0.27$ & 0.04 & $-0.04,0.13$ & 0.07 & $-0 \cdot 01,0 \cdot 14$ \\
\hline & 2 & $0 \cdot 14$ & $-0.14,0.43$ & 0.06 & $-0 \cdot 15,0.22$ & -0.01 & $-0.08,0.09$ & 0.04 & $-0 \cdot 06,0 \cdot 11$ \\
\hline \multirow[t]{2}{*}{ Breakfast cereals } & 1 & $0.31^{*}$ & $0 \cdot 02,0 \cdot 61$ & $0 \cdot 20$ & $-0.02,0.40$ & $0.09^{\star}$ & $0.02,0.20$ & $0 \cdot 15^{\star}$ & $0.04,0.26$ \\
\hline & 2 & $0 \cdot 11$ & $-0.20,0.42$ & $0 \cdot 11$ & $-0 \cdot 10,0.32$ & 0.05 & $-0.02,0.15$ & $0 \cdot 11$ & $-0.01,0.23$ \\
\hline \multirow[t]{2}{*}{ White bread } & 1 & $0 \cdot 49^{\star *}$ & $0 \cdot 17,0 \cdot 80$ & $0 \cdot 11^{*}$ & $0.02,0.40$ & 0.09 & $-0.01,0.17$ & $0 \cdot 12^{*}$ & $0.02,0.21$ \\
\hline & 2 & 0.24 & $-0.05,0.53$ & $0 \cdot 10$ & $-0.08,0.28$ & 0.02 & $-0 \cdot 08,0 \cdot 10$ & 0.05 & $-0.06,0.16$ \\
\hline
\end{tabular}

Model 1: adjusted for gender, clustered by school.

Model 2: adjusted for BMI, parental education, Index of Multiple Deprivation score, location and gender, clustered by school.

Coefficient was significant: ${ }^{\star} P<0 \cdot 05,{ }^{\star *} P<0 \cdot 01$. 
Associations with the density of convenience store provision were less strong, although an increased density of convenience stores in the local area was associated with a significant increase in consumption of fruit juices (Table 4).

\section{Other food retailers}

For both distance and density, there were no consistent statistically significant associations with food intake (Tables 3 and 4).

\section{Takeaways}

Living further away from takeaways was associated with more favourable food intakes, as consumption of crisps, chocolate, sugary soft drinks and white bread was negatively associated in both models (Table 3). Associations were weaker for density (Table 4), although vegetable intakes were higher with increasing density $(0 \cdot 12$ portions/week increase in vegetable consumption per outlet per $\mathrm{km}^{2}$ increase, $\left.P<0 \cdot 05\right)$.

\section{Discussion}

Our analyses suggest that both distance to and density of local food outlets were associated with food intake in children. Close proximity to supermarkets and convenience stores was generally associated with a higher prevalence of reporting of unhealthy food choices, and reduced consumption of fruits and vegetables. Closer proximity to convenience stores was also associated with higher reported intakes of snack foods, including sweets, chocolates and crisps. These associations were observed even after adjusting for major influences on food intake, including location, socio-economic status and BMI. A high density of supermarkets and convenience stores in the neighbourhood was associated with higher fruit and vegetable intakes, and this observation was statistically significant for supermarket access. However, the density of supermarkets was also associated with increased intakes of some unhealthy snacks, including sugary drinks and sweets. Although we found evidence of effects, overall the observed effect sizes were small, suggesting that distance to and density of food outlets in the neighbourhood play only a minor role in influencing food consumption patterns in these children.

This is one of the first studies to have taken an integrated approach to address the combined effects of the local food environment, such as distance to and density of food outlets in the local environment ${ }^{(4,7,11,13,19)}$. Our findings on the effects of distance and density are in agreement with previous research in other countries. With regard to distance to food outlets, in a US study, living closer to small food stores and fast-food retailers resulted in lower consumption of fruits and vegetables ${ }^{(16)}$. To date there are fewer data available on neighbourhood density of food outlets and food choice in children, but recently Timperio et $a l^{(14)}$ found that a higher density of fast-food retailers and convenience stores was associated with lower levels of fruit and vegetable intake in Australian children. In another study, access to multinational fast-food outlets was not related to fruit consumption in adults, but living further away was associated with higher vegetable intakes, while access to locally operated fast-food outlets was not related to fruit and vegetable intake ${ }^{(17)}$.

Our findings support the limited evidence from previous research in the UK, and suggest that proximity to a wide variety of food choices does not necessarily lead to optimal food intake ${ }^{(26,27)}$. Our results also concur with another UK study ${ }^{(18)}$ which showed that children from similar socio-economic backgrounds, but who lived in divergent environmental conditions, had differing eating habits. It was found that those children who lived in the area with a higher density, safety of access to and longer opening hours of shops made poorer food choices. In our work, the children who lived furthest from shops generally had the healthiest food choices, but the impact of both distance to and density of food outlets on food choice was small, suggesting that other factors may play a more important role in food choice in children. For example, the foods available at or around school may influence children's food choice, and associations may possibly be influenced by fruit and vegetable preferences, but to date interventions to improve healthy food availability have had limited success ${ }^{(16,28)}$.

The finding that close proximity to supermarkets was related to reduced consumption of fruits and vegetables, while the density of supermarkets in the area was positively related to increased vegetable consumption, is difficult to explain. The implications of these findings are unclear, but the increased fruit and vegetable intake by children who lived further away from supermarkets may in part be explained by the high proportion of children who lived in rural communities in our study, who may have more access to locally produced produce/homegrown fruit and vegetables. The finding that high density was associated with increased intakes of both healthy and unhealthy food choices is also difficult to explain but may relate to increased availability, choice and bulk purchasing of all food types in supermarkets.

Our study has a number of strengths and limitations. Currently the relationship between food choice in the local environment is relatively under-investigated, with those studies that have been undertaken often not taking an integrated approach to address the combined effects of distance to and density of food outlets in the neighbourhood in relation to intake in children ${ }^{(4,7,11,13,19)}$. By using a validated survey instrument together with a well-characterised sample of children, and combining information on reported frequency of consumption of key food items with a detailed GIS database on the location, type and accessibility of food retailers, we have provided new 
evidence on associations between the neighbourhood food environment and dietary choice in UK children.

In terms of limitations, our study is cross-sectional in nature and therefore we are limited in our ability to ascribe causality to the associations detected. The data collection was carried out in the school summer term and, owing to greater availability and range of fruit and vegetables during this season ${ }^{(29)}$, recorded intakes may not reflect average intake over a year. Although we used a detailed and contemporary GIS database of food store locations, it is likely that some facilities we included were no longer open, while newly opened outlets were excluded. Our sampling strategy was designed to achieve maximum environmental heterogeneity in order to address questions relating to environmental influences on behaviour, and that led to deliberate oversampling from schools in rural areas, which may limit comparisons with other studies that have predominantly been undertaken in large urban areas. Proximity and density of food outlets may be indicative of a number of environmental factors, and although in our analyses we attempted to account for this by adjusting for IMD, there may be other environmental factors that have not been accounted for. Furthermore, as the SPEEDY study was carried out in an area of the UK with a low proportion of families from different ethnic backgrounds, our final sample is mainly white, with only $3 \cdot 8 \%$ of children from other ethnic backgrounds. Although this is representative of the Norfolk population, it means we were unable to examine how associations varied with ethnicity.

The short HBSC questionnaire was used to assess intake of the most commonly consumed foods rather than exact intake of nutrients, in order to provide simple information on trends in dietary intake. We used the HBSC FFQ because it is known that children's recall of food intake is prone to reporting errors ${ }^{(30,31)}$ and it has been previously validated ${ }^{(24)}$; patterns of food consumption in the present study are largely in agreement with more precise dietary methodology used in the UK National Diet and Nutrition Survey in children aged 7-10 years $^{(32)}$.

In conclusion, our findings show that the impact of both distance and density of food outlets on children's food choice was small, with close proximity to supermarkets and convenience stores being associated with reduced consumption of fruits and vegetables, and proximity to convenience stores associated with higher intakes of snacks and confectionery. Conversely, a high neighbourhood density of supermarkets and convenience stores was associated with higher fruit and vegetable intakes and, for supermarkets only, higher intakes of snacks and confectionery. Despite the small magnitude of the associations we detected, the effects of individual foods combined could be important, particularly as even small differences in intake can contribute to the onset of childhood obesity.

\section{Acknowledgements}

This research was funded by the National Prevention Research Initiative (http://www.npri.org.uk) with support from the following organisations: British Heart Foundation; Cancer Research UK; Chief Scientist Office, Scottish Government Health Directorate; Department of Health; Diabetes UK; Economic and Social Research Council; Health \& Social Care Research \& Development Office for Northern Ireland; Medical Research Council; Welsh Assembly Government; and World Cancer Research Fund. None of the authors has a conflict of interest. S.G., E.v.S., P.S., A.C. and A.J. were responsible for conception of the study, study design, setup, and data collection and processing. F.H. participated in data collection and processing. P.S. and A.W. analysed the data and P.S. tabulated the data. P.S., A.W. and A.C. drafted the manuscript. I.H. assisted with drafting the manuscript. All authors were involved with data interpretation and critical revisions of the paper, and provided approval for publication.

\section{References}

1. Williams CL \& Strobino BA (2008) Childhood diet, overweight, and CVD risk factors: the Healthy Start project. Prev Cardiol 11, 11-20.

2. Mikkilä V, Räsänen L, Raitakari OT et al. (2007) Major dietary patterns and cardiovascular risk factors from childhood to adulthood. The Cardiovascular Risk in Young Finns Study. Br J Nutr 98, 218-225.

3. Cali AM \& Caprio S (2008) Obesity in children and adolescents. J Clin Endocrinol Metab 93, 11 Suppl. 1, S31-S36.

4. Friel S, Walsh O \& McCarthy D (2006) The irony of a rich country: issues of financial access to and availability of healthy food in the Republic of Ireland. I Epidemiol Community Health 60, 1013-1019.

5. Estaquio C, Druesne-Pecollo N, Latino-Martel P et al. (2008) Socioeconomic differences in fruit and vegetable consumption among middle-aged French adults: adherence to the $5 \mathrm{a}$ day recommendation. J Am Diet Assoc 108, 2021-2030.

6. Martikainen P, Brunner E \& Marmot M (2003) Socioeconomic differences in dietary patterns among middleaged men and women. Soc Sci Med 56, 1397-1410.

7. Wang MC, Kim S, Gonzalez AA et al. (2007) Socioeconomic and food-related physical characteristics of the neighbourhood environment are associated with body mass index. J Epidemiol Community Health 61, 491-498.

8. Macdonald L, Cummins S \& Macintyre S (2007) Neighbourhood fast food environment and area deprivation substitution or concentration? Appetite 49, 251-254.

9. Morland K, Wing S \& Diez Roux A (2007) The contextual effect of the local food environment on residents' diets: the Atherosclerosis Risk in Communities study. Am J Public Health 92, 1761-1767.

10. Block JP, Scribner RA \& DeSalvo KB (2004) Fast food, race/ ethnicity, and income: a geographic analysis. Am J Prev Med 27, 211-217.

11. Kipke MD, Iverson E, Moore D et al. (2007) Food and park environments: neighborhood-level risks for childhood obesity in east Los Angeles. J Adolesc Health 40, 325-333.

12. Macintyre S (2007) Deprivation amplification revisited; or, is it always true that poorer places have poorer access to resources for healthy diets and physical activity? Int J Behav Nutr Phys Act 4, 32-36. 
13. Pearson T, Russell J, Campbell MJ et al. (2005) Do 'food deserts' influence fruit and vegetable consumption? - A cross-sectional study. Appetite 45, 195-197.

14. Timperio A, Ball K, Roberts R et al. (2008) Children's fruit and vegetable intake: associations with the neighbourhood food environment. Prev Med 46, 331-335.

15. Merchant AT, Dehghan M, Behnke-Cook D et al. (2007) Diet, physical activity, and adiposity in children in poor and rich neighbourhoods: a cross-sectional comparison. Nutr J 6, 1.

16. Jago R, Baranowski T, Baranowski JC et al. (2007) Distance to food stores and adolescent male fruit and vegetable consumption: mediation effects. Int J Behav Nutr Phys Act 4, 35 .

17. Pearce J, Hiscock R, Blakely T et al. (2009) A national study of the association between neighbourhood access to fastfood outlets and the diet and weight of local residents. Health Place 15, 193-197.

18. Hackett A, Boddy L, Boothby J et al. (2008) Mapping dietary habits may provide clues about the factors that determine food choice. J Hum Nutr Diet 21, 428-437.

19. Larsen K \& Gilliland J (2008) Mapping the evolution of 'food deserts' in a Canadian city: supermarket accessibility in London, Ontario, 1961-2005. Int J Health Geogr 7, 16-20.

20. van Sluijs EM, Skidmore PM, Mwanza K et al. (2008) Physical activity and dietary behaviour in a populationbased sample of British 10-year old children: the SPEEDY study (Sport, Physical activity and Eating behaviour: Environmental Determinants in Young people). BMC Public Health 8, 388.

21. Bibby P \& Shepherd J (2004) Developing a New Classification of Urban and Rural Areas for Policy Purposes - The Methods. London: RERC, School of Town and Regional Planning, University of Sheffield and Birkbeck College, University of London.

22. Cole TJ, Bellizzi MC, Flegal KM et al. (2000) Establishing a standard definition for child overweight and obesity worldwide: international survey. BMJ 320, 1240-1243.
23. Noble M, Wright G, Dibben C et al. (2004) Indices of Deprivation 2004. Report to the Office of the Deputy Prime Minister. London: Neighbourhood Renewal Unit.

24. Vereecken CA \& Maes L (2003) A Belgian study on the reliability and relative validity of the Health Behaviour in School-Aged Children food-frequency questionnaire. Public Health Nutr 6, 581-588.

25. Goldstein H (2003) Multilevel Statistical Models, 3rd ed. London: Hodder Arnold.

26. Cummins S \& Macintyre S (2006) Food environments and obesity - neighbourhood or nation? Int J Epidemiol 35, 100-104.

27. Dibsdall LA, Lambert N, Bobbin RF et al. (2003) Lowincome consumers' attitudes and behaviour towards access, availability and motivation to eat fruit and vegetables. Public Health Nutr 6, 159-168.

28. Moore L \& Tapper K (2008) The impact of school fruit tuck shops and school food policies on children's fruit consumption: a cluster randomised trial of schools in deprived areas. J Epidemiol Community Health 62, 926-931.

29. Givens ML, Lu C, Bartell SM et al. (2007) Estimating dietary consumption patterns among children: a comparison between cross-sectional and longitudinal study designs. Environ Res 103, 325-330.

30. Domel SB (1997) Self-reports of diet: how children remember what they have eaten. Am J Clin Nutr 65, 4 Suppl., 1148S-1152S.

31. Crawford PB, Obarzanek E, Morrison J et al. (1994) Comparative advantage of 3-day food records over 24hour recall and 5-day food frequency validated by observation of 9- and 10-year-old girls. J Am Diet Assoc 94, 626-630.

32. Gregory J \& Lowe S (2000) National Diet and Nutrition Survey: Young People Aged 4 to 18 Years. vol. 1: Report of the Diet and Nutrition Survey. London: The Stationery Office. 